\title{
Direct effects of poly( $\varepsilon$-caprolactone) lipid-core nanocapsules on human immune cells
}

\author{
Silvana Sandri*,1 ${ }^{1}$ Cristina Bichels Hebeda ${ }^{1}$, Rodrigo Azevedo Loiola ${ }^{1}$, Selma Calgaroto ${ }^{2}$, \\ Mayara Klimuk Uchiyama ${ }^{3}$, Koiti Araki ${ }^{3}$, Luiza Abrahão Frank ${ }^{4}$, Karina Paese ${ }^{2,4}$, Silvia \\ Stanisçuaski Guterres ${ }^{4}$, Adriana Raffin Pohlmann ${ }^{2,4}$ \& Sandra Helena Poliselli Farsky ${ }^{1}$ \\ ${ }^{1}$ Department of Clinical \& Toxicological Analyses, School of Pharmaceutical Sciences, University of São Paulo, Brazil \\ ${ }^{2}$ Department of Organic Chemistry, Postgraduate Program in Chemistry, Institute of Chemistry, Federal University of Rio Grande do \\ Sul, Porto Alegre, Brazil \\ ${ }^{3}$ Department of Fundamental Chemistry, Institute of Chemistry, University of São Paulo, Brazil \\ ${ }^{4}$ Department of Production and Control of Pharmaceutics; Postgraduate Program in Pharmaceutical Sciences, Faculty of \\ Pharmaceutical Sciences, Federal University of Rio Grande do Sul, Brazil. \\ *Author for correspondence: Tel.. +55 11309 12197; ssandri@usp.br
}

Aim: Poly( $\varepsilon$-caprolactone) lipid-core nanocapsules (LNCs) are efficient drug carriers and drug-free LNCs display therapeutic effects, inhibiting tumor growth and neutrophil activities. Herein, we investigated the direct actions of LNCs on human immune cells, to guide their therapeutic application. Materials \& methods: LNC's uptake, cytokine release, cell migration, proliferation and intracellular pathways under inflammatory stimulation were investigated. Results \& conclusion: LNCs quickly penetrated leukocytes without cytotoxicity; inhibited mitogen-induced lymphocyte proliferation, cytokine release and leukocyte migration under inflammatory stimulation, which were associated with inhibition of the MAP kinase pathway and intracellular calcium influx. Hence, we showed LNCs as a down-regulatory agent on immune cells, suggesting that either the particles themselves or their application as a drug carrier can halt non-desired inflammatory processes.

\section{Graphical abstract:}

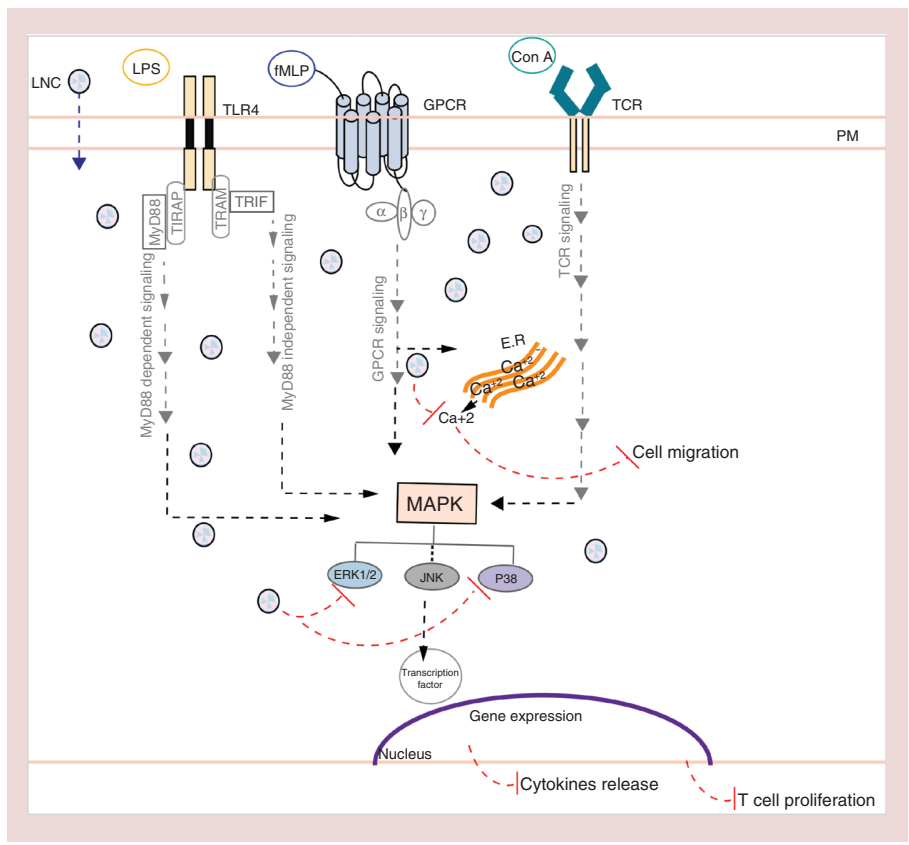

First draft submitted: 13 December 2018; Accepted for publication: 27 February 2019; Published online: 6 June 2019 
Keywords: cell migration • cytokines release • immunosuppression • MAPK signaling • peripheral blood mononuclear cells $\bullet$ polymorphonuclear cells

Over the last few years, several preclinical studies have pointed out the potential therapeutic benefits of nanotechnology to improve the efficacy of human disease treatments. In fact, there are a considerable number of nanoparticle (NP)-based drug formulations available for clinical use nowadays, such as liposomes, polymers, micelles, nanocrystals, metals/metal oxides and other inorganic materials and proteins $[1,2]$. Although several NP-based drug formulations have been introduced into clinical practice, many have failed to meet regulatory criteria for approval or have exhibited modest effects in Phase III clinical studies [3]. One of the reasons for the low effectiveness of nanoformulations is the lack of knowledge regarding their interaction with the host, especially the immune system [4-6]. Thus, a systematic characterization of the biological effects of nanoformulations in human leukocytes is needed to improve their therapeutic efficacy, enabling exploring the full clinical potential of drug carriers [7].

A poly( $\varepsilon$-caprolactone) lipid-core nanocapsule (PCL-LNCs) is a vesicular carrier comprising a core structured by the dispersion of solid lipid (sorbitan monostearate) and liquid lipid (caprylic/capric triglyceride [CCT]) surrounded by a polymeric wall $[8,9]$. PCL-LNCs present biodegradability and biocompatibility, which turn it into a promising drug carrier with a high potential for therapeutic applications [10,11]. In this way, it has been shown there is a therapeutic benefit of PCL-LNCs loaded with different molecules for treatment of cancer [12-16], inflammatory conditions [17-19] and neurodegenerative diseases [20]. Beyond its potential use as a drug carrier, we had previously shown that drug-free LNCs display in vitro and in vivo beneficial effects. Indeed, oral treatment with drug-free LNCs reduced cutaneous melanoma lesions in mice by delaying the melanoma cell cycle and evoking cell death [15]. More recently, the toxicity mechanism of drug-free LNCs in the case of melanoma was enlarged, demonstrating its interference in melanoma-neutrophil crosstalk. In this respect, melanoma cells treated with drug-free LNCs secreted lower amounts of TGF- $\beta$, leading to the switch of co-cultured neutrophils to an antitumoural phenotype (N1) and higher production of reactive oxygen species [21]. Moreover, intravenous administration of drug-free LNCs-impaired neutrophil interactions in microcirculatory vessel walls [21], underscoring anti-inflammatory and antimetastatic mechanisms of LNCs.

Considering the great possibility of the application of drug-loaded LNCs in the treatment of severe and chronic diseases, it is fundamental to expand the understanding of the effects of drug-free LNCs in the immune system. The present study was designed in order to evaluate the effect of drug-free LNCs on the inflammatory profile of immune cells and unravel the intracellular mechanisms involved in their biological effects. Herein, we show that LNCs are quickly up taken by immune cells and significantly inhibit ERK1/2 and p38 phosphorylation and intracellular calcium mobilization, affecting cytokine release and migration of mononuclear and polymorphonuclear cells from peripheral blood.

\section{Materials \& methods}

Preparation \& characterization of LNCS

LNCs were prepared following the method previously reported [8]. Briefly, PCL Mw $14 \mathrm{~kg} / \mathrm{mol}$ (Sigma-Aldrich, MO, USA), sorbitan monostearate (0.038 g; Sigma-Aldrich) and CCT mixture ( $0.160 \mathrm{ml}$; Alpha Química, Porto Alegre, Brazil) were dissolved in acetone $(25 \mathrm{ml}$, nuclear, analytical grade) and ethanol $(2 \mathrm{ml}$, nuclear, analytical grade). The organic phase was stirred at $40^{\circ} \mathrm{C}$ until complete dissolution of all components. The aqueous phase was composed of polysorbate 80 (0.078 g; Oxiteno SA, São Paulo, Brazil) and water (53 ml, ultrapure grade), and was also stirred at $40^{\circ} \mathrm{C}$. Then, the organic phase was injected into the aqueous phase using a funnel with a approximately $3 \mathrm{~mm}$ outlet under magnetic stirring. The turbid solution was stirred for $10 \mathrm{~min}$ at $40^{\circ} \mathrm{C}$ to eliminate the organic solvents, and then the formulation was concentrated to $10 \mathrm{ml}$ in a rotatory evaporator (R-114; Büchi, Flawil, Switzerland). The formulation was sterilized by filtration $\left(0.22 \mu \mathrm{m}\right.$, Millex ${ }^{\circledR}{ }_{-} \mathrm{GV}$ sterile, Millipore, MA, USA). To verify the efficacy of sterilization, $20 \mu \mathrm{l}$ of formulation were inoculated in a blood agar and Sabouraud plate for bacterial and fungal detection, respectively, according to Paese and collaborators [9,22].

The formulation was analyzed by laser diffraction (LD; Mastersizer 2000, Malvern Instruments Ltd, Malvern, UK) and the samples were directly inserted into the dispersion accessory containing distilled water to obtain more than $2 \%$ obscuration and the background signal was measured before each analysis. The formulations were also characterized by dynamic light scattering (DLS; ZetaSizer Nano ZS, Malvern Instruments Ltd). The z-average values were determined after diluting the samples $(500 \times)$ in ultrapure and filtered water $(0.45 \mu \mathrm{m})$. The particle number density was determined using a ZetaView ${ }^{\circledR}$ instrument (ZetaView, Particle Metrix, Inning am Ammersee, 
Germany) at room temperature. The instrument is equipped with a built-in cell and a LD microscope with a video camera (CCD) to capture the motion of the particles. The analytical software, ZetaView (version 8.02.30.02), was applied. The light scattering by each particle moving under Brownian motion is recorded with this technique. The formulations were diluted $(1: 20,000 \mathrm{v} / \mathrm{v}$ and $1: 15 \mathrm{v} / \mathrm{v})$ in ultrapure water and injected into the cell with a sterile glass syringe $(5 \mathrm{ml}$ capacity) until the liquid reached the tip of the nozzle. The $\zeta$ potential was determined by electrophoretic light scattering (ZetaSizer Nano ZS, Malvern Instruments Ltd) after dilution $(500 \times)$ of the sample in filtered $(0.45 \mu \mathrm{m}) 10 \mathrm{mmol} / 1 \mathrm{NaCl}$ aqueous solution.

\section{Immune cells isolation \& culture}

Human peripheral blood cells were isolated from fresh and heparinized venous blood from healthy donors by density-gradient centrifugation, as described previously [23,24]. Blood drawing followed a protocol approved by the School of Pharmaceutical Sciences Ethical Committee at the University of São Paulo (CEP Approval no. 52267215.2.0000.0067). Isolated peripheral blood mononuclear cells (PBMCs) and polymorphonuclear cells (PMNs) were cultured in Roswell Park Memorial Institute 1640 medium (RPMI; Thermo Fischer, MA, USA) supplemented with 10\% fetal bovine serum (FBS; Thermo Fischer), $100 \mathrm{IU} / \mathrm{ml}$ penicillin and $100 \mu \mathrm{g} / \mathrm{ml}$ streptomycin (Thermo Fischer) in the absence and presence of LNCs. According to the assay, the cells were also stimulated with lipopolysaccharide (LPS; E. coli; serotype 026:B6; Sigma-Aldrich) or N-Formyl-Met-Leu-Phe (fMLP; SigmaAldrich) and maintained in the absence and presence of LNCs under standard culture conditions in a humidified incubator at $37^{\circ} \mathrm{C}$ with $5 \% \mathrm{CO}_{2}$.

Human umbilical vein endothelial cells

Human umbilical vein endothelial cells (HUVECs) were grown in RPMI containing 10\% FBS and 1\% antibiotics (100 units $/ \mathrm{ml}$ penicillin, $100 \mu \mathrm{g} / \mathrm{ml}$ streptomycin) under standard conditions in a humidified incubator at $37^{\circ} \mathrm{C}$ with $5 \% \mathrm{CO}_{2}$.

\section{In vitro cellular uptake}

The uptake of LNCs by PBMCs and PMNs was established by enhanced dark-field hyperspectral microscopy $\left(\right.$ CytoViva $\left.{ }^{\circledR}\right)$. Using a 96-well plate, $1 \times 10^{6}$ cells/well were incubated with increasing concentrations of LNCs $\left(0.13 \times 10^{11}-5.2 \times 10^{11} \mathrm{LNCs} / \mathrm{ml}\right)$ and incubated for 2 or $24 \mathrm{~h}$. A control group was maintained in the presence of the RPMI 10\% FBS (nontreated [NT]) without LNCs. Afterwards, carefully recovered cells were washed threetimes with warm sterile phosphate buffered saline (PBS) supplemented with 5\% FBS by centrifugation. Then, $10 \mu \mathrm{l}$ of cell solution were set up using extra clean dust-free slides (Nexterion ${ }^{\circledR}$ Glass B; Schott, NY, USA) and coverslips (Nexterion Glass D \#D263T; Schott). Immune cells were imaged using a CytoViva Ultra Resolution Imaging System (CytoViva, Inc., AL, USA) mounted on an Olympus BX51 microscope $(\times 1500$ magnification; Olympus Corporation, Tokyo, Japan) equipped with a fluorite $100 \times$ oil iris $0.6-1.30$ numerical aperture (NA) objective and $75 \mathrm{~W}$ Xe light source. Optical images were taken using a Q-imaging Retiga EXi CCD camera (Olympus Corporation, PA, USA) and Dage XL CCD digital camera with Image Processing Software (Dage ${ }^{\circledR}$; DAGE-MTI of MC, Inc., MI, USA).

\section{Cell viability}

To verify the alteration of these LNCs in cell viability, PBMCs or PMNs $\left(5 \times 10^{5}\right.$ cells/well) were cultured with increasing concentrations of LNCs $\left(0.13 \times 10^{11}-5.2 \times 10^{11} \mathrm{LNCs} / \mathrm{ml}\right)$ for $24 \mathrm{~h}$. After incubation, cells were washed twice with warm PBS and viability was determined with propidium iodide (PI; Sigma-Aldrich) and Annexin $\mathrm{V}$ (AnxV; BD Biosciences, CA, USA) incorporation. Briefly, cells were washed twice in PBS and incubated with AnxV (1:20) in the binding buffer for $20 \mathrm{~min}$ in the dark at room temperature. Then, $0.5 \mu \mathrm{l}$ of PI was added and 10,000 events were acquired in a flow cytometer Accuri C6 (BD Biosciences). As a positive control for apoptosis and necrosis, cells were incubated at $65^{\circ} \mathrm{C}$ for $5 \mathrm{~min}$ and stained with $\mathrm{AnxV}$ and PI, respectively.

\section{Lymphocyte proliferation assay}

To monitor lymphocyte proliferation, carboxyfluorescein succinimidyl ester(CFSE)-labeling was performed as described previously [25]. Briefly, PBMCs $\left(1 \times 10^{7}\right)$ were stained with $1 \mu \mathrm{M}$ CFSE; Thermo Fischer $)$ for 10 min at $37^{\circ} \mathrm{C}$, washed twice with PBS containing $10 \% \mathrm{FBS}$ and resuspended in RPMI complete medium. Then, PBMCs $\left(5.0 \times 10^{5}\right.$ cells/well) were cultured on a U-bottom 96-well plate (Corning, NY, USA) with $10 \mu \mathrm{g} / \mathrm{ml}$ Concanavalin 
A (Con A; Sigma-Aldrich) and different concentrations of LNCs $\left(0.13 \times 10^{11}-5.2 \times 10^{11} \mathrm{LNCs} / \mathrm{ml}\right)$ for $72 \mathrm{~h}$. Cells were harvested and the fluorescence intensity of CFSE-labeled cells was measured. Cells were acquired in an Accuri C6 flow cytometer (BD Biosciences) and 30,000 events were considered for analyses.

\section{Immunoassay}

PBMCs $\left(5 \times 10^{5}\right.$ cells/well $)$ were incubated with $5 \mu \mathrm{g} / \mathrm{ml}$ LPS and PMNs $\left(5 \times 10^{5}\right.$ cells/well $)$ with $50 \mathrm{nM} \mathrm{fMLP}$ in the absence (basal) or presence of LNCs at different concentrations $\left(0.13 \times 10^{11}-5.2 \times 10^{11} \mathrm{LNCs} / \mathrm{ml}\right)$ for 24 $h$. The supernatant was recovered and levels of TNF- $\alpha$, IL- 8 and IL- 10 were quantified with ELISA Ready-SET-GO - 2nd Generation (Thermo Fischer) according to the manufacturer's instructions.

\section{Membrane marker}

To evaluate of impact of LNCs treatment on TLR4 expression, PBMCs $\left(5 \times 10^{5}\right.$ cells/well $)$ were incubated with $5 \mu \mathrm{g} / \mathrm{ml}$ LPS and LNCs at a concentration of $5.2 \times 10^{11} \mathrm{LNCs} / \mathrm{ml}$ for $2 \mathrm{~h}$. Thereafter, cells were harvested, washed twice with PBS and labeled with conjugated antibody anti-TLR4-phycoerythrine (PE; BD Biosciences) for $30 \mathrm{~min}$ at room temperature and in the dark. Cells were acquired in an Accuri C6 flow cytometer (BD Biosciences) and 10,000 events were considered for analyses. Data present percentage of positive cells.

\section{Phosphorylated proteins}

PBMCs or PMNs $\left(5 \times 10^{5}\right.$ cells/well $)$ were pre-incubated with LNCs $\left(5.2 \times 10^{11} \mathrm{LNCs} / \mathrm{ml}\right)$ for $2 \mathrm{~h}$ and washed twice in RPMI complete medium. PBMCs and PMNs were stimulated with $5 \mu \mathrm{g} / \mathrm{ml}$ LPS and $50 \mathrm{nM}$ fMLP, respectively, and incubated for the stipulated time. Then, the cells were fixed with FACS Lysing (BD Biosciences) for $20 \mathrm{~min}$ at room temperature, washed with $0.1 \mathrm{M}$ glycine and washed with PBS containing $1 \%$ bovine serum albumin (BSA; Sigma-Aldrich). Cells were permeabilized with $0.001 \%$ Triton X (Sigma-Aldrich) over 30 min at room temperature. Afterward, the cells were centrifuged ( $600 \mathrm{~g} ; 7 \mathrm{~min}$; room temperature) and incubated with purified primary antibody anti-phospho ERK1/2 (Abcam, Cambridge, UK), anti-ERK1/2 (Abcam), anti-p38 (Cell Signaling, MA, USA) and anti-phospho p38 (Abcam) overnight at $4{ }^{\circ} \mathrm{C}$. After the incubation period, cells were washed with PBS containing 1\% BSA and incubated with secondary antibodies conjugated with PE (Abcam) and fluorescein isothiocyanate (FITC; Abcam) for $1 \mathrm{~h}$ at room temperature. In sequence, 30,000 events were acquired on an Accuri C6 flow cytometer (BD Biosciences). Data present percentage of positive cells.

\section{Boyden chamber assay}

Immune cell migration was performed according to de Lima and collaborators [26]. PBMCs or PMNs $\left(2.5 \times 10^{6} / \mathrm{ml}\right)$ pretreated with LNCs $\left(5.2 \times 10^{11} \mathrm{LNCs} / \mathrm{ml}\right)$ were resuspended in $30 \mu \mathrm{l}$ Hanks balanced salt solution (HBSS) supplemented with $0.05 \%$ BSA (Sigma-Aldrich) and transferred to the upper compartment of a ChemoTx-101-8 microplate (Neuro Probe, Inc., MD, USA). The bottom part of the microplate was filled with $300 \mu$ l of chemotactic inducer $\left(50 \mathrm{nM}\right.$ fMLP). The microplate was incubated under controlled conditions $\left(37^{\circ} \mathrm{C}, 5 \% \mathrm{CO}_{2}\right)$ for $2 \mathrm{~h}$. Cell numbers in the bottom compartments were obtained via a hemocytometer and optical microscope. The assay was performed in triplicate.

\section{Transmigration assay through HUVECs}

A transmigration assay was performed according to the method previously reported [27] with slight modifications. PBMCs or PMNs transmigration was performed with a Transwell ${ }^{\circledR}$ insert (membrane diameter: $6.5 \mathrm{~mm} ; 3 \mu \mathrm{m}$ porosity; Corning) containing HUVECs. Briefly, HUVECs $\left(5 \times 10^{4}\right.$ cells) were cultured on the bottom of the Transwell insert in RPMI supplemented with 10\% FBS until 80\% of confluence. The inserts were embedded on a 24-well plate culture (Corning). Thus, PBMCs or PMNs were previously treated with $5.2 \times 10^{11} \mathrm{LNCs} / \mathrm{ml}$ and washed twice in HBSS. In sequence, $1 \times 10^{6}$ cells were incubated with HUVECs in a Transwell system over $4 \mathrm{~h}$ at $37^{\circ} \mathrm{C}$ with $5 \% \mathrm{CO}_{2}$ and a humid atmosphere. Transmigrated cells were collected from the bottom compartment by aspirating the medium and counted using a hemocytometer and optical microscope. Afterward, the inserts were removed, washed in PBS twice and adhered cells were stained with antibody anti-CD45 conjugated with FITC (BD Biosciences) for $40 \mathrm{~min}$ at $37^{\circ} \mathrm{C}$. In sequence, cells were washed again with PBS and the inserts were inverted and placed on $5 \mu$ l of Vectashield (VectorLabs, CA, USA) mounting medium for fluorescence. Samples were covered with glass coverslips and at least ten different fields were analyzed using a fluorescence microscope (Imager A2 Zeiss Microscope, Jena, Germany). The number of adhered leukocytes was identified as CD45 positive cells. 
Table 1. Lipid-core nanocapsules characterization.

\begin{tabular}{|lll}
\hline Method and parameter & Result & Ref. \\
\hline$d_{\mathrm{v}}(\mathrm{nm})$ & $185 \pm 25$ \\
\hline Span & $1.5 \pm 0.1$ \\
\hline$d(0.5)_{n}(\mathrm{~nm})$ & $66 \pm 2.5$ \\
\hline $\mathrm{z}$-Average diameter $(\mathrm{nm})$ & $183 \pm 17$ \\
\hline PDI & $0.10 \pm 0.04$ \\
\hline$\zeta$ potential $(\mathrm{mV})$ & $-9.6 \pm 2$ \\
\hline pH & $4.9 \pm 0.3$ \\
\hline PND (particles ml $\left.{ }^{-1}\right)$ & $(6.4 \pm 0.2) \times 10^{13}$ \\
\hline PDI: Polydispersity index; PND: Particle number density \\
\hline
\end{tabular}

\section{Calcium influx}

PBMCs $\left(5 \times 10^{5}\right.$ cells/well $)$ were pre-incubated with LNCs $\left(5.2 \times 10^{11} \mathrm{LNCs} / \mathrm{ml}\right)$ for $2 \mathrm{~h}$ and washed twice in PBS. Afterward, the cells were incubated with Fluor-4/AM prepared with anhydrous dimethyl sulfoxide (Thermo Fischer) at a concentration of $3 \mu \mathrm{M}$ for $45 \mathrm{~min}$ at room temperature in the dark. Next, cells were washed twice at room temperature in HBSS containing $20 \mathrm{mM} \mathrm{HEPES}$ and $0.2 \% \mathrm{BSA}(\mathrm{pH} 7.4$ ) to remove the extracellular dye. After the second wash, cells were incubated in the absence or presence of $50 \mathrm{nM}$ fMLP for 3 min. The intensity of fluorescence was measured on a microplate reader (Synergy HTX, Biotek, VT, USA). The negative control consisted of the cells incubated without Fluo-4/AM. Data present the median of fluorescence intensity.

\section{Statistical analyses}

Statistical analyses were performed with one- or two-way analysis of variance (ANOVA) as appropriate with post hoc comparisons using the Tukey test. The values are presented as mean \pm standard error of mean. All calculations were performed with GraphPad Prism version 7.0 (GraphPad Software, CA, USA). The level of significance was set at $\mathrm{p}<0.05$.

\section{Results}

\section{LNCs characterization}

LNCs formulations were prepared according to Jager and colleagues [9], which was characterized macroscopically as a white opalescent liquid. LNC suspension has unimodal size distribution whatever the technique used: LD or DLS (Supplementary Figure 1A \& B). The results of those analyses are described in Table 1. LD and DLS showed mean diameter of roughly $180 \mathrm{~nm}, \zeta$ potential was slightly negative owing to the polyester shell coated with a nonionic surfactant (polysorbate 80). After sterilization, the characteristics were maintained and microbiological assays indicated the absence of microorganism growth (Supplementary Figure 1C\&D), as observed by Paese and collaborators along with Calgaroto and collaborators [9-11].

\section{LNCs were internalized by immune cells and did not alter cell viability, but inhibited cell}

\section{proliferation}

A concentration-response analysis of the nanoparticle uptake at $0.13 \times 10^{11}, 2.6 \times 10^{11}$ and $5.2 \times 10^{11} \mathrm{LNCs} / \mathrm{ml}$ was performed by CytoViva ${ }^{\circledR}$ microscopy. This range of LNCs concentration was based in our previous in vivo and in vitro studies and it was considered a safe range to preclude the physic effect on cell culture, avoiding cell death [15,21]. As shown in Figure 1A \& B, the LNCs uptake by PBMCs and PMNs was concentration-dependent from $2 \mathrm{~h}$ of culture. After $24 \mathrm{~h}$, LNCs remained in the cell cytoplasm; however, there were no differences among the concentrations tested (Supplementary Figure 2A \& B). At LNCs concentrations used, the nanocapsules:cell ratio was $77,400: 1 ; 154,000: 1$ and 300,000:1 for $0.13 ; 2.6$ and $5.2 \times 10^{11} \mathrm{LNCs} / \mathrm{ml}$, respectively. It is noteworthy that LNCs at different concentrations did not trigger either apoptosis or necrosis after $24 \mathrm{~h}$ of culturing in PBMCs and PMNs as evaluated by AnxV and PI incorporation, respectively (Figure 1C\&D). Furthermore, the LNCs effects on lymphocyte proliferation were assessed by concanavalin A (Con A) stimulation, a mitogen usually employed to mimic in vitro T-cell proliferation [28], and LNCs at different concentrations for $72 \mathrm{~h}$. LNCs alone were not able to induce cell proliferation (Supplementary Figure 3A \& B). Conversely, LNCs at 2.6 or $5.2 \times 10^{11} \mathrm{LNCs} / \mathrm{ml}$ 

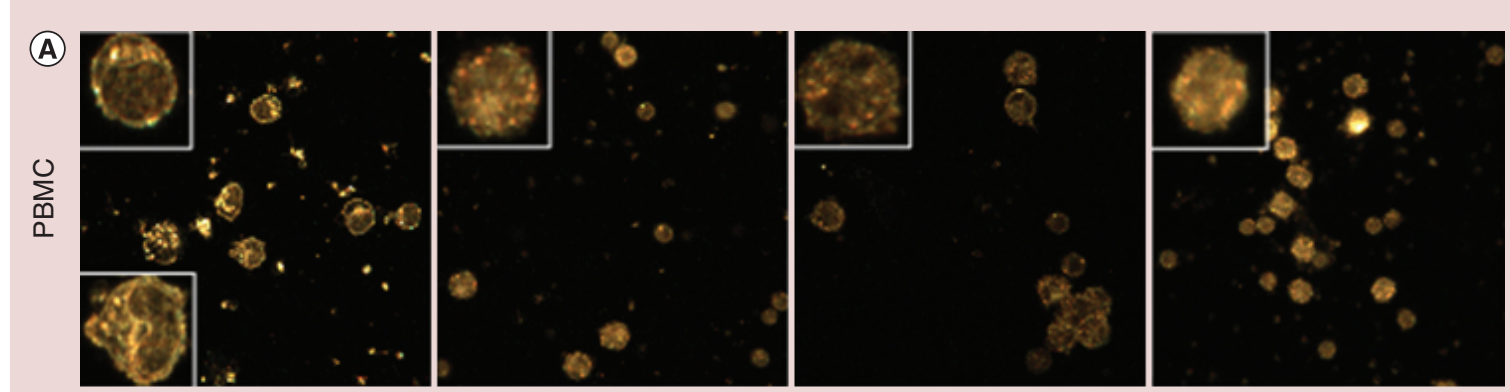

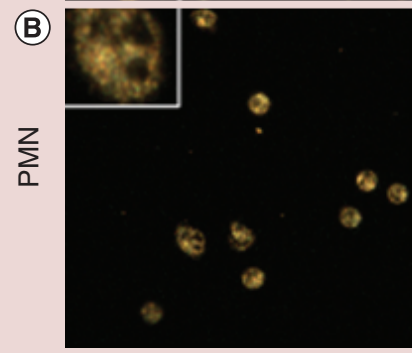

NT

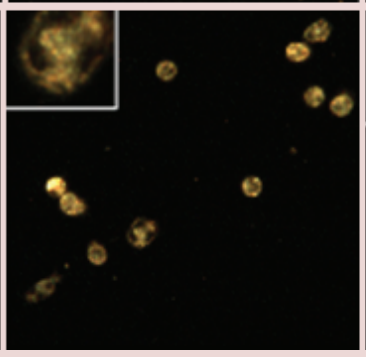

0.13

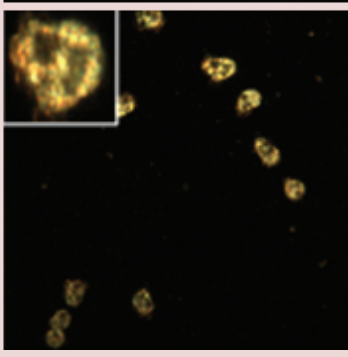

2.6

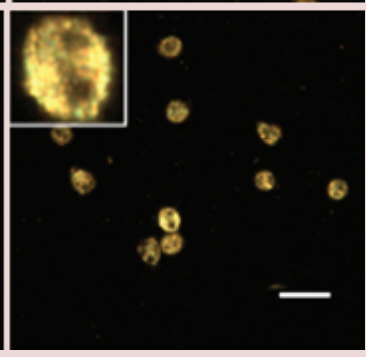

5.2

$\times 10^{11} \mathrm{LNCs} / \mathrm{ml}$

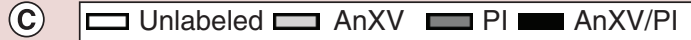

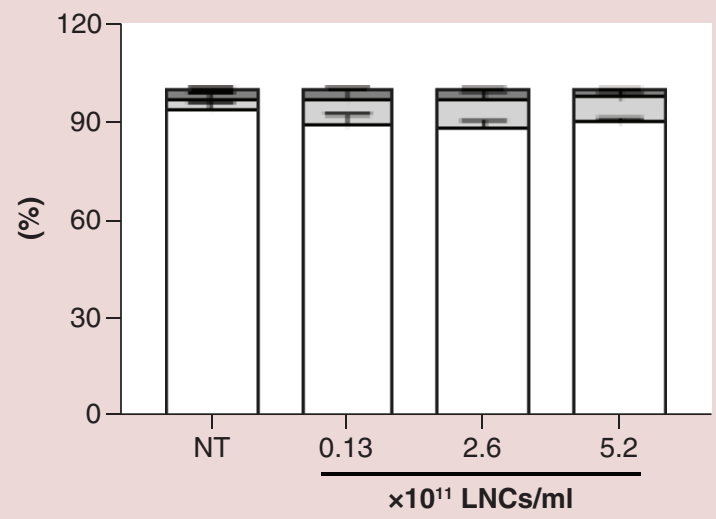

(D)
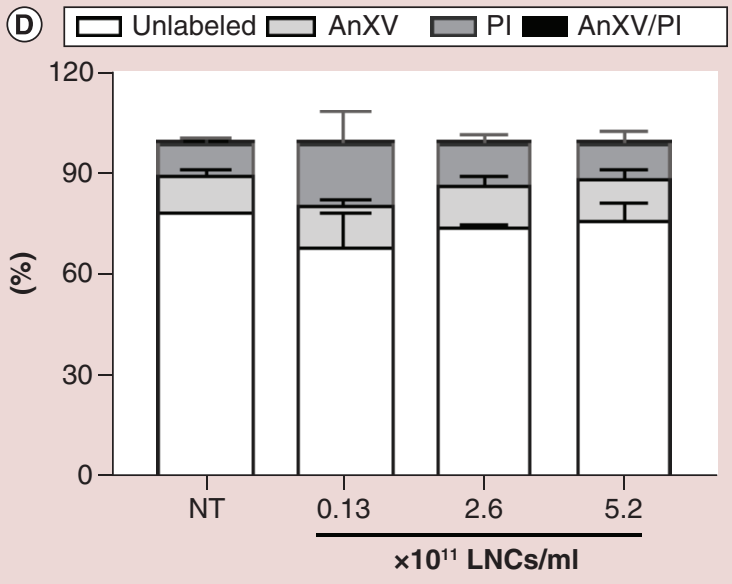

Figure 1. Lipid-core nanocapsules up taken did not alter cell viability and inhibited cell proliferation.

Photomicrography of LNCs uptake by PBMCs and PMNs. (A \& B) Immune cells were incubated with LNCs at indicated concentrations for $2 \mathrm{~h}$. The images were captured using CytoViva ${ }^{\circledR}$ microscopy $(100 \times$ magnificence; $20 \mu \mathrm{m}$ scale bar). LNCs did not alter the cell viability of the PBMCs (C) or PMNs (D) after $24 \mathrm{~h}$ of culturing. LNCs impaired T-cell proliferation induced by mitogenic ConA (E\&F). PBMCs were cultured with LNCs at indicated concentrations and Con A for $72 \mathrm{~h}$. The data are expressed as mean \pm standard error of mean of at least three to five independent experiments.

${ }^{*} p<0.05$ Con A versus basal.

${ }^{* *} \mathrm{p}<0.05$ LNCs versus Con A.

AnXV: Annexin V; CFSE: Carboxyfluorescein succinimidyl ester; Con A: Concanavalin A; LNC: Lipid-core nanocapsule; NT: Non-treated; PBMC: Peripheral blood mononuclear cell; PI: Propium iodide; PMN: Polymorphonuclear.

concentrations decreased cell proliferation of Con A-activated lymphocytes (Figure 1E\&F). This reduction of T-cell proliferation was not related to cell death (Supplementary Figure 3C).

LNCs impaired the secretory ability of stimulated immune cells

Cytokine production and release from immune cells play critical roles in response to infection, inflammation and tissue injury/repair [29]. Herein, LNCs effects were evaluated in terms of secretory immune cell functioning at the basal and stimulated conditions after $24 \mathrm{~h}$ of culture. LNCs perse inhibited basal secretion of TNF- $\alpha$, IL- 8 and IL-10 


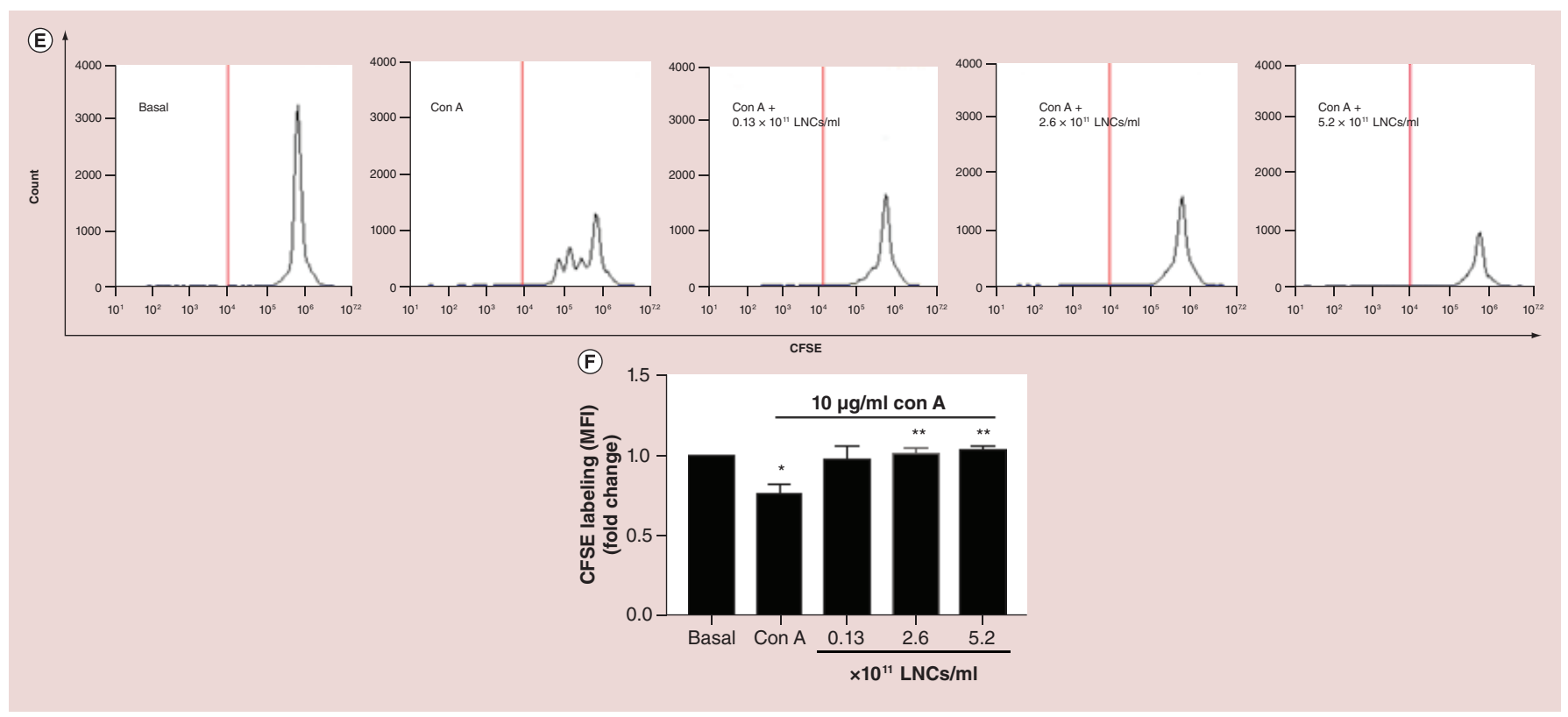

Figure 1. Lipid-core nanocapsules up taken did not alter cell viability and inhibited cell proliferation (cont.). Photomicrography of LNCs uptake by PBMCs and PMNs. (A \& B) Immune cells were incubated with LNCs at indicated concentrations for $2 \mathrm{~h}$. The images were captured using CytoViva ${ }^{\circledR}$ microscopy $(100 \times$ magnificence; $20 \mu \mathrm{m}$ scale bar). LNCs did not alter the cell viability of the PBMCs (C) or PMNs (D) after $24 \mathrm{~h}$ of culturing. LNCs impaired T-cell proliferation induced by mitogenic ConA (E\&F). PBMCs were cultured with LNCs at indicated concentrations and Con A for $72 \mathrm{~h}$. The data are expressed as mean \pm standard error of mean of at least three to five independent experiments.

${ }^{*} \mathrm{p}<0.05$ Con A versus basal.

${ }^{* *} p<0.05$ LNCS versus Con A.

AnXV: Annexin V; CFSE: Carboxyfluorescein succinimidyl ester; Con A: Concanavalin A; LNC: Lipid-core nanocapsule; NT: Non-treated; PBMC: Peripheral blood mononuclear cell; PI: Propium iodide; PMN: Polymorphonuclear.

by PBMCs (Supplementary Figure 4A-C). In order to investigate the role of LNCs under the stimulated conditions, stimuli were employed that acted through different receptors. LPS that promotes activation of TLR4 [30] and fMLP, acting via G-protein receptors (GPCRs) [31], were used to activate PBMCs and PMNs, respectively. As expected, LPS increased the secretion of TNF- $\alpha$, IL-8 and IL-10 by PBMCs (Figure 2A-C). LNCs treatments inhibited the secretion of TNF- $\alpha$ and IL-10 in a concentration-dependent manner (Figure 2A\&C), and at concentrations of 0.13 and $5.2 \times 10^{11} \mathrm{LNCs} / \mathrm{ml}$ impaired LPS-induced IL-8 secretion (Figure 2B). Additionally, LNCs, in a concentration-dependent manner, impaired IL-8 secretion by PMNs under basal conditions (Supplementary Figure 4D). Under fMLP-stimulated condition, only $5.2 \times 10^{11} \mathrm{LNCs} / \mathrm{ml}$ was able to diminish IL-8 secretion (Figure 2D).

\section{LNCs inhibited immune cell trafficking following chemotactic stimulus}

Leukocyte migration, a critical step of the immune response, is a prerequisite to the entry of cells, such as neutrophils, monocytes and effector-T cells to sites of infection and/or injury within the interstitium [32]. Therefore, herein, we investigated the role of LNCs on leukocyte migration. Thus, PBMCs were previously treated with LNCs for $2 \mathrm{~h}$ and migration was evaluated by a modified Boyden chamber assay in the absence or presence of fMLP. As expected, after $2 \mathrm{~h}$ of incubation, fMLP induced PBMCs migration to the bottom chamber (Figure 3A). LNCs treatment did not modify the migration of PBMCs in the absence of chemotactic inducer; however, LNCs treatment remarkably inhibited PBMCs migration evoked by fMLP (Figure 3A). Furthermore, we evaluated the effect of LNCs on PBMCs migration in a co-culture system with endothelial cells (HUVECs), which simulated certain aspects of the human vascular barrier. In agreement with our previous results, it was established that LNCs again inhibited the migration of the PBMCs induced by AMLP, whereas it had no effect under basal conditions (Figure 3B). Additionally, we assessed leukocyte adherence at the top of the HUVECs monolayer by CD45 labeling (leukocyte-pan marker). As shown in Figure 3C, the number of adhered PBMCs previously treated with LNCs was higher in comparison to untreated cells in the presence of fMLP, confirming that LNCs inhibit the chemoattractant 

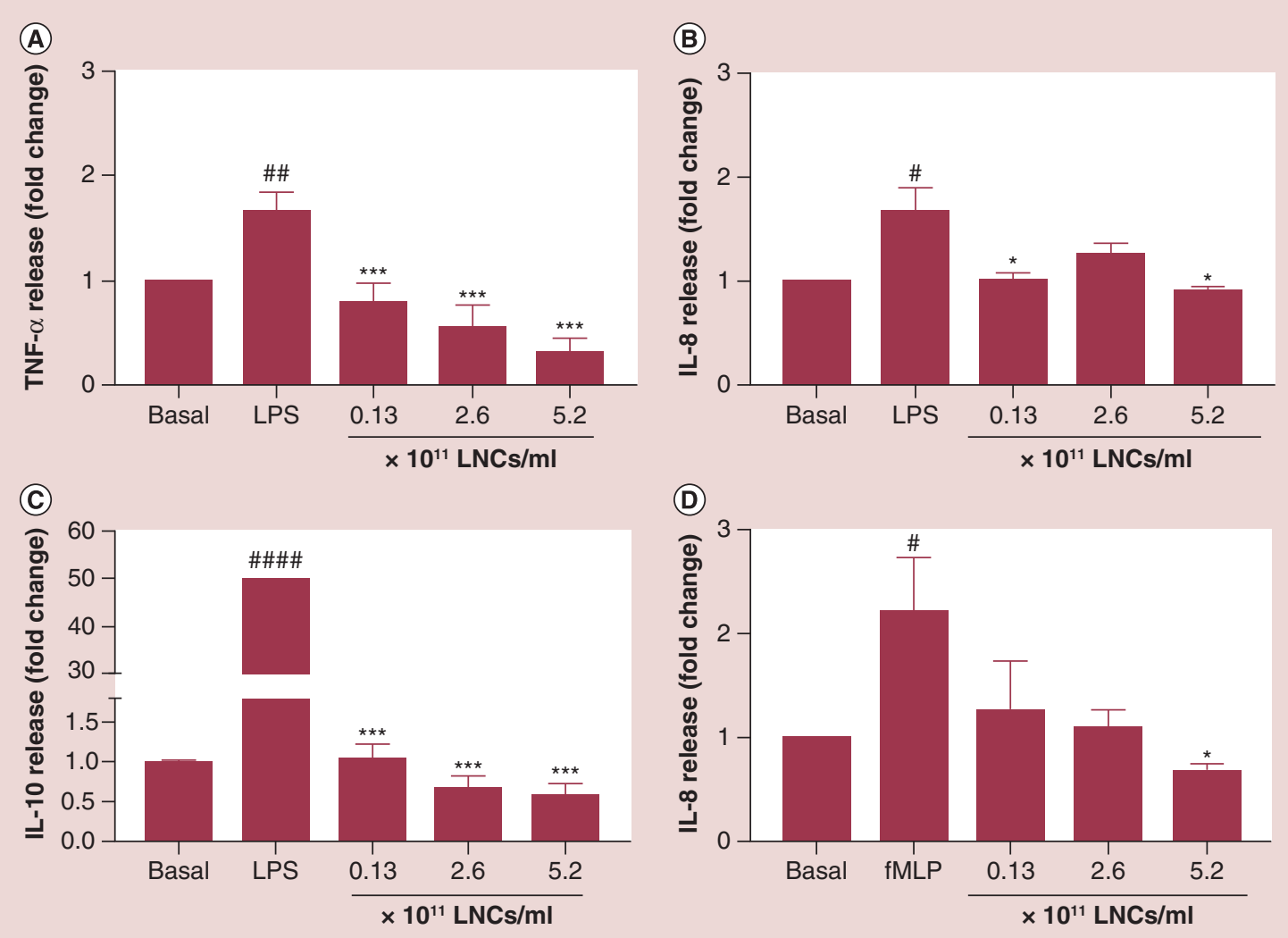

Figure 2. Effects of lipid-core nanocapsules on cytokine secretion by immune cells. LNCs decreased TNF- $\alpha$ (A), IL-8 (B) and IL-10 (C) secretion by LPS-stimulated PBMCs; and IL-8 release (D) by fMLP-stimulated PMNs. PBMCs or PMNs were incubated with LNCs at indicated concentrations in the absence or presence of $5 \mu \mathrm{g} / \mathrm{ml}$ LPS or $50 \mathrm{nM}$ fMLP for $24 \mathrm{~h}$. Cytokine secretion was measured in the supernatant by ELISA. The data are expressed as mean \pm standard error of mean of at least three to five independent experiments.

$\# p<0.05 ;$;\# $p<0.01$; \#\#\# $p<0.001$ LPS or fMLP versus basal. * $\mathrm{p}<0.05 ; * * * \mathrm{p}<0.001$ LNCs versus LPS or fMLP. fMLP: N-Formyl-Met-Leu-Phe; LNC: Lipid-core nanocapsule; PBMC: Peripheral blood mononuclear cell; PMN: Polymorphonuclear.

activity of this compound. Considering that leukocyte activation and, subsequently, transmigration is dependent on calcium mobilization, we analyzed its intracellular levels using Fluoro-4/AM, a fluorescent calcium probe. As shown in Figure 3D, fMLP enhanced intracellular levels of calcium in PBMCs and LNCs abrogated this effect. It was also observed there was a reduction of PMNs migration induced by fMLP in the Boyden chamber as well as in the co-culturing system (Figure $3 \mathrm{E} \& \mathrm{~F}$ ).

\section{LNCs target MAPK pathway to impair the immune cell functions}

MAPK signaling controls many aspects of the immune response, from the initiation phase of innate immunity, to activation of adaptive immunity, to cell death when immune functioning is complete [33]. In order to clarify the mechanism associated with LNCs' inhibitory effects on immune cells, we evaluated whether LNCs influenced the expression of TLR4, the LPS recognition receptor, and activation of members of MAPK signaling.

First, PBMCs were incubated with LNCs for $2 \mathrm{~h}$, washed and then stimulated or not with LPS for $2 \mathrm{~h}$. Under those conditions, LNCs did not significantly modify TLR4 expression on PBMCs (Supplementary Figure 5). To assess MAPK activation, PBMCs were previously incubated with LNCs for $2 \mathrm{~h}$, washed, LPS-stimulated for 15 min and both ERK1/2 and p38 activation were analyzed by flow cytometry. As observed in Figure 4A \& B, LNCs did not alter proteins phosphorylation under basal conditions. As expected, LPS increased the phosphorylation of ERK1/2 and p38 after 15 min of stimulation. The LNCs pretreatment significantly prevented LPS-induced ERK1/2 and p38 activation (Figure 4A \& B). The fMLP signaling also included MAPK activation [34]. Herein, we 
(A)

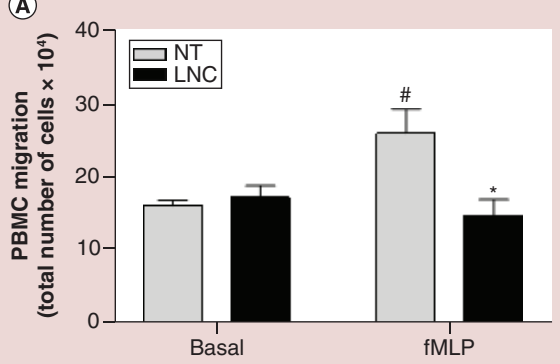

(B)
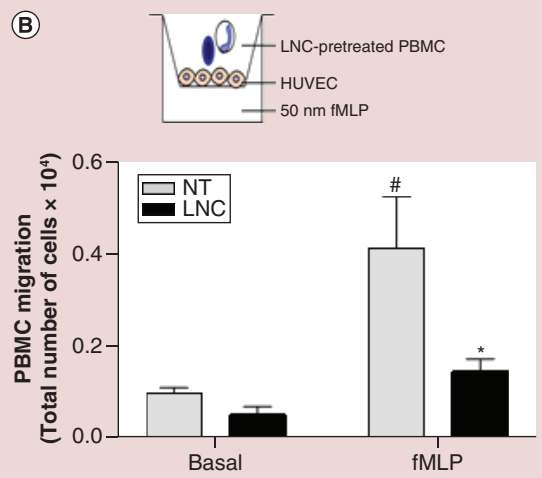

(c)

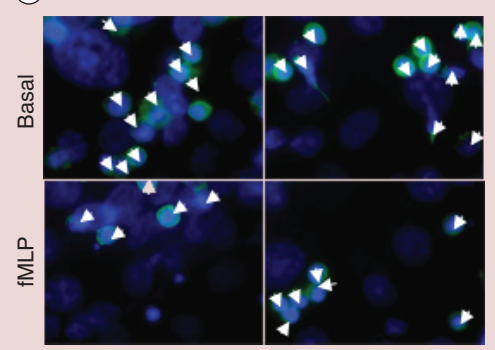

(D)

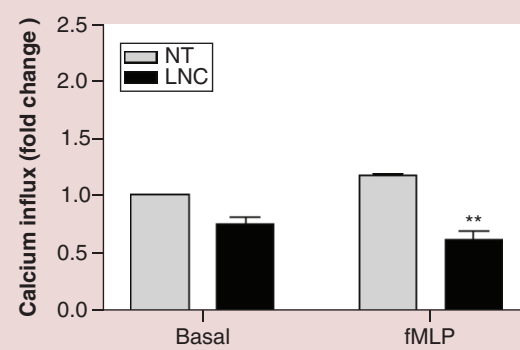

(E)

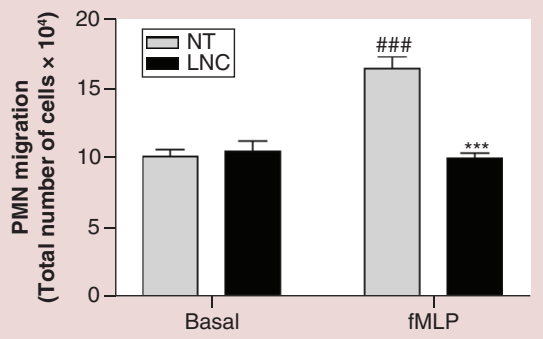

(F)
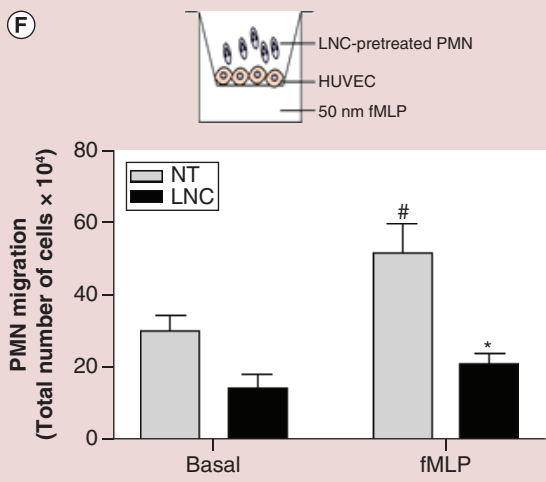

Figure 3. Effects of lipid-core nanocapsules on immune cell migration and calcium influx. LNCs reduced fMLP-induced PBMCs migration in the Boyden chamber (A) and within the in vitro system of PBMCs/HUVECs co-culturing (B). LNCs increased the number of CD45-positive cells adhered to the HUVECs monolayer (C). Effects of LNCs on fMLP-induced calcium influx in PBMCs (D). LNCs reduced the fMLP-induced PMNs migration within the Boyden chamber (E) and within the in vitro system of the PMNCs/HUVECs co-culture (F). PBMCs or PMNs were pre-incubated with LNCs $\left(5.2 \times 10^{11} \mathrm{LNCs} / \mathrm{ml}\right)$ for $2 \mathrm{~h}$ and seeded in the Boyden chamber or in the leukocyte/HUVECs co-culture, which contained $50 \mathrm{nM}$ fMLP in the bottom of chambers. The data are expressed as mean \pm standard error of mean of at least three to five independent experiments.

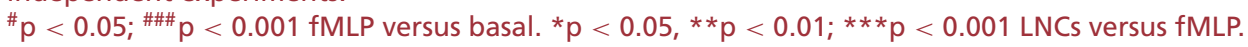

fMLP: N-Formyl-Met-Leu-Phe; HUVEC: Human umbilical vein endothelial cell; LNC: Lipid-core nanocapsule; NT: Non treated; PBMC:

Peripheral blood mononuclear cell; PMN: Polymorphonuclear.

found fMLP effectively induced ERK1/2 and p38 activation in PMNs after 5 min of stimulation. As observed in PBMCs, LNCs pretreatment abrogated proteins phosphorylation induced by fMLP in PMNs (Figure 4C \& D).

\section{Discussion}

Elucidating the effect of nanoparticles interaction with immune cells is imperative to improve therapeutic outcomes of nanoparticle systems and prevent undesired effects in clinical approaches $[7,35,36]$. LNCs have been used as a drug carrier for the treatment of various experimental disease models, highlighting their potential as promising drug carriers for clinical therapy [37]. Thought-provoking, drug-free LNCs activity affect immune cells [15,21], addressing the fundamental analyses of these nanostructures with respect to immune intracellular pathways. In this work, we showed that drug-free LNCs are efficiently up taken by human PBMCs and PMNs without cytotoxic effects and display immune regulatory functions, influencing the phosphorylation of MAPK and calcium mobilization. It is noteworthy that LNCs suspension exhibited a narrow size distribution with no micro aggregates as well as free microorganisms contamination.

Corroborating our previous studies [12,21], we here confirmed that LNCs prompted penetrated into cytoplasm of human PMBCs and PMNs without causing cell death. The LNCs concentrations employed in the present study exhibited a therapeutic efficacy in experimental models of melanoma and glioma in mice when daily administered by oral or intravenous routes for seven or 21 days $[15,21,38]$.

It was also found that LNCs presented an antiproliferative effect on lymphocytes in response to mitogen stimulation. This effect was not associated with cell death. Con A, a T-cell mitogen that is widely used, promotes T-cell proliferation by binding to a mannose moiety of cell surface glycoproteins, including the T-cell receptor [39] and activating CD28 [40]. The activation of T-cell receptor and CD28 co-stimulatory molecule activates a variety 
(A)

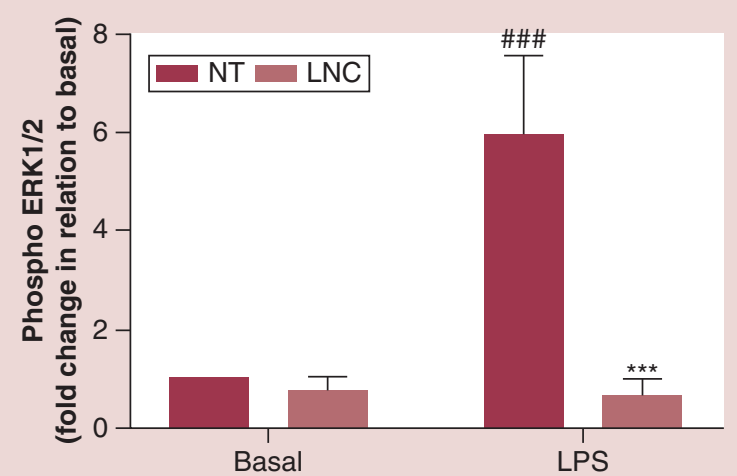

(C)

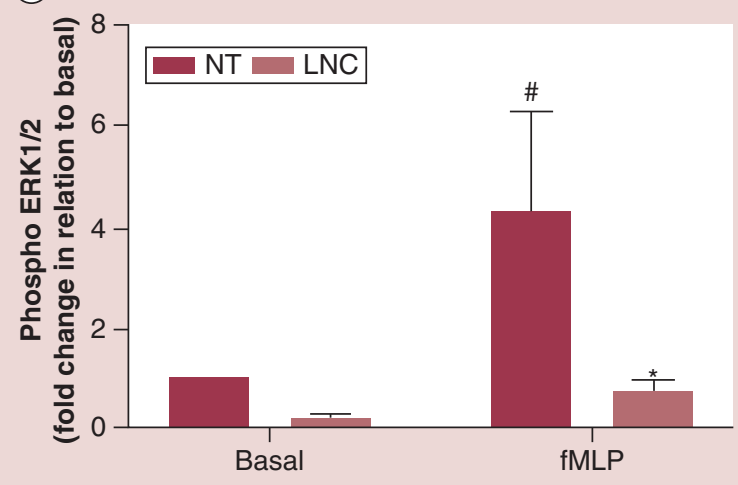

(B)

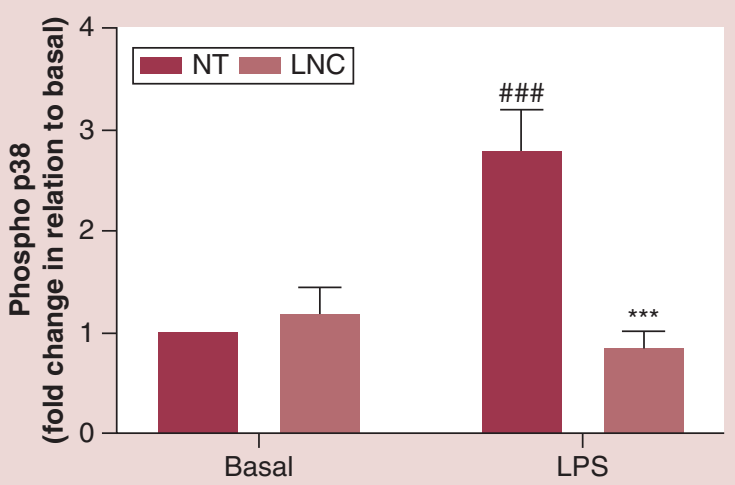

(D)

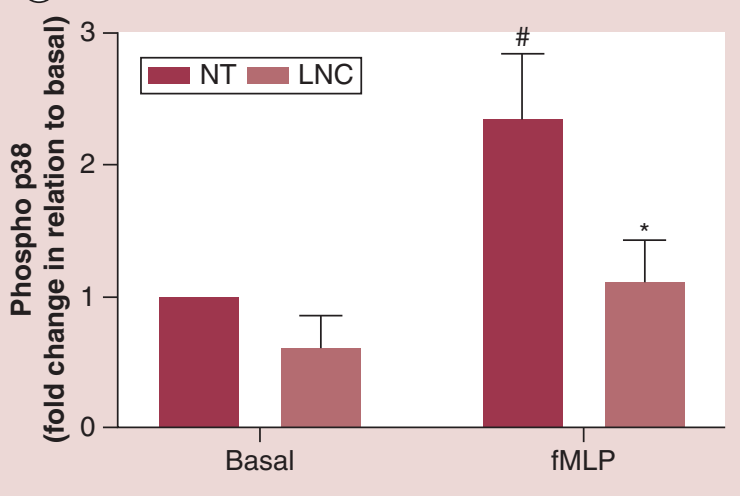

Figure 4. Effects of lipid-core nanocapsules on MAPK pathway. Immune cells were pre-incubated with LNCS $\left(5.2 \times 10^{11} \mathrm{LNCs} / \mathrm{ml}\right)$ for $2 \mathrm{~h}$ and stimulated with $5 \mu \mathrm{g} / \mathrm{ml}$ LPS or $50 \mathrm{nM}$ fMLP for 15 and 5 min, respectively. LNCs inhibited ERK $1 / 2$ and p38 phosphorylation in LPS-stimulated PBMCs (A \& B) and fMLP-stimulated PMNs (C \& D). Protein phosphorylation was assessed by flow cytometry. The data are expressed as mean \pm standard error of mean.of at least six to nine independent experiments.

${ }^{\#} p<0.05 ; \# \# p<0.001$ LPS or fMLP versus basal; $* p<0.05$ and $* * * p<0.001$ LNCs versus LPS or fMLP. fMLP:N-Formyl-Met-Leu-Phe; LNC: Lipid-core nanocapsule; LPS: lipopolysaccharide; NT: Non treated.

of intracellular pathways, such as the PI3K pathway, which has calcium release assemblies from the endoplasmic reticulum and MAPK, thus regulating the various functions of $\mathrm{T}$ cells as proliferation [41]. Therefore, the inhibition of T-cell proliferation brought about by LNCs may be related to impaired MAPK activation or calcium mobilization.

The immune response depends on the activation of a variety of receptors, intracellular signaling pathways and transcription factors that yield the synthesis of proteins over the course of host defense [42]. A range of expressed membrane receptors in immune cells recognizes motifs from pathogens as TLR4, the LPS recognition receptor, and GPCRs, associated with the activation of cell migration induced by formyl peptides, including those from bacterial walls [43]. TLR4 and GPCRs are promptly activated at the beginning of infectious processes and trigger complex intracellular signaling cascades to secrete inflammatory mediators and induce migration of circulating leukocytes at the site of lesion $[44,45]$. Our data clearly show that LNCs, once internalized by PBMCs and PMNs, inhibit the initial stages of the immune response by impairing secretion of cytokines (TNF- $\alpha$, IL-8) and cell transmigration. The latter effect corroborates our previous data showing intravenous administration of LNCs reduced interaction of circulating leukocytes within endothelial cellular microcirculation of mice [21]. Undoubtedly, the perfect binding of blood leukocytes into endothelial cells of postcapillary venules is fundamental to leukocyte transmigration by the vessel wall and migration into the inflammatory site [45]. Here, we have shown there to be LNCs-induced reduction of calcium mobilization on PBMCs, which can explain, at least in part, the impairment of fMLP-induced cell migration by LNCs. 
Interestingly, we found that IL-10 secretion was also inhibited by LNCs treatment. Beyond the inflammation control, IL-10 operates in tumors modulating the microenvironment to the benefit of tumor progression [46]. The current data are supported by our previous report showing that LNCs regulate melanoma-neutrophil crosstalk, reducing IL-10 and other immunosuppressive molecules [21]. It has been extensively shown that immune cells in melanoma promote the development of tumors by releasing protumour mediators, such as growth factors, metalloproteinases and immunosuppressive mediators $[47,48]$. Hence, it may be supposed that effects caused by LNCs here detected may be a complementary therapeutic mechanism of LNCs found in a melanoma in vivo model [15].

Activation of TLR4 prompts assembly of the adaptor proteins, MyD88 and MAL/TIRAP that signal to activate nuclear transcription factors or phosphorylation of MAPK. Subsequently, ERK1/2, JNK and p38 phosphorylation activates transcription factors to induce inflammatory cytokine secretion [49]. Similarly, the disassembly subunits of G-protein triggered by GPCR agonists, such as fMLP, activates kinases and leads to phosphorylation of MEK and ERK1/2, as well as mobilization of calcium into the cytoplasm. The GPCR-induced pathway controls cell proliferation, differentiation and migration [50,51]. As LNCs treatment inhibited cytokine secretion and cell migration induced by LPS and fMLP, we investigated the actions of LNCs on a common pathway activated by both stimuli. For the first time, we here point out the ability of drug-free LNCs to affect the phosphorylation of ERK1/2 and $\mathrm{p} 38$ proteins, which is independent of inflammatory stimuli (LPS or fMLP) and cell type (mononuclear or polymorphonuclear cells). Also, we may suppose the effect does not reflect modification of inflammatory receptors in the cell membrane, once TLR4 expression in PBMCs were not modified by LNCs treatment.

The current study highlighted important features of LNCs on the immune system and contributed to the understanding of its biological effect and higher efficacy as a drug carrier. Nonetheless, further studies are necessary to elucidate the mechanism involved in LNCs-induced inhibition of MAPK pathway and its consequences on leukocyte functioning. For instance, previous study showed that CCT solutions did not reduce the melanoma growth when administered by oral route [15], supporting the hypothesis that the supramolecular structure of the LNCs may inhibit phosphorylation of proteins. In addition, the down-regulatory immune effects induced by drug-free LNCs on immune response may support their application as an alternative therapeutic itself, combined with drugs or as drug carrier with off-target effects. Based on their action on inhibiting cell migration and cytokine release, it may be supposed that LNCs should be applied to halt undesired inflammatory reactions, itself or as a drug carrier. For instance, the higher efficacy of methotrexate-loaded LNC was already shown in the experimental model of arthritis [18], a disease characterized by a massive influx of immune cells [52]. Furthermore, previous study of our group has reported the ability of LNCs to cross the blood-brain barrier increasing the delivery of medicines into the brain, pointing out LNCs application as carrier of drugs for treatments of neurological diseases, such as glioma and Alzheimer's $[12,20,38]$. Specifically to the immune system, LNCs could be co-adjuvant for the treatment of cancer as melanoma, which the immune cells and secreted mediators in the tumour microenvironment contribute to disease progression and the relapse during treatment regime $[48,53]$.

\section{Conclusion}

In this study, we report, for the first time, the interaction of drug-free LNCs with human immune cells using an ex vivo model. Our data indicate that LNCs are internalized by cells from peripheral blood and act intracellularly to reduce cytokine secretion and cell transmigration. The knowledge of real actions of nanocarrier systems on immune cells must be carefully investigated, especially in terms of those promptly up-taken by cells. Considering that clinical trials have failed, in part, based on a lack of data surrounding the impact of these drug carriers on the immune system, our findings highlight the importance to evaluate the interaction of nanostructures with immune system.

\section{Future perspective}

Further investigations are desirable to reveal the mechanism of LNCs on intracellular pathways and investigate the role of the nanostructures formed by CCT. In addition, the knowledge obtained here will guide investigations about the potential of the drug-free LNCs itself or combined with current therapies to treat arthritis, neurological diseases and cancer. 
Summary points

- Peripheral human immune cells internalize lipid-core nanocapsules (LNCS).

- LNCs decrease T-cell proliferation activated by the mitogen, Concanavalin A.

- LNCs inhibit the initial steps of the immune response by impairing the secretion of TNF- $\alpha$, IL- 8 and IL-10 by LPS-stimulated peripheral blood mononuclear cells; and IL-8 by fMLP-stimulated polymorphonuclears.

- LNCs reduce immune cells migration induced by fMLP.

- The inhibitory effects of LNCs are related to the reduction of MAPK pathway activation (p38 and ERK 1/2) and intracellular calcium mobilization.

Open access

This work is licensed under the Attribution-NonCommercial-NoDerivatives 4.0 Unported License. To view a copy of this license, visit http://creativecommons.org/licenses/by-nc-nd/4.0/

Supplementary data

To view the supplementary data that accompany this paper please visit the journal website at: www.futuremedicine.com/doi/full/ 10.2217/nme-2018-0484

\section{Acknowledgments}

We would like to thank the Full Professor A Campa for donating the HUVECs; the Laboratory Specialist S Migliorini for support in blood collection; and the Associate Professor EMG Shinohara for donation of the anti-CD45 antibody. All of them are from Department of Clinical Chemistry \& Toxicology, School of Pharmaceutical Sciences, University of São Paulo. We also thank Professor J Rubio (Departamento de Engenharia de Minas, Metalúrgica e de Materiais, UFRGS) for the facilities provided regarding the use of ZetaView equipment.

\section{Financial \& competing interests disclosure}

This study was supported by São Paulo Research Foundation (grant no. 2014/07328-4) and Coordination for the Improvement of Higher Level -or Education- Personnel (CAPES; PNPD Postdoctoral fellowship [no. 1569289]). Moreover, this study was financed in part by the Research Support Foundation of the State of Rio Grande do Sul (FAPERGS: PRONEX and Pesquisador Gaúcho) and by the National Council of Technological and Scientific Development (CNPq), as well as by the CAPES - Finance Code 001. The authors have no other relevant affiliations or financial involvement with any organization or entity with a financial interest in or financial conflict with the subject matter or materials discussed in the manuscript apart from those disclosed.

Writing assistance was provided by Cambridge Proofreading LLC and was funded by CNPq.

Ethical conduct of research

Written consent was obtained prior to blood collection. Ethical committee approval for this study was granted by the School of Pharmaceutical Sciences, University of São Paulo, following the norms as per the Declaration of Helsinki. Patients were provided with information forms describing the study, which was also approved by the ethics committee. All signed consent forms were stored in case of an audit. Blood drawing followed a protocol approved by the School of Pharmaceutical Sciences Ethical Committee at the University of São Paulo (CEP Approval no. 52267215.2.0000.0067). HUVECs were kindly donated by A Campa from the School of Pharmaceutical Sciences/University of São Paulo.

\section{References}

Papers of special note have been highlighted as: $\bullet$ of interest; $\bullet \bullet$ of considerable interest

1. Bobo D, Robinson KJ, Islam J, Thurecht KJ, Corrie SR. Nanoparticle-based medicines: a review of FDA-approved materials and clinical trials to date. Pharm. Res. 33(10), 2373-2387 (2016).

2. Ventola CL. Progress in nanomedicine: approved and investigational nanodrugs. P.T. 42(12), 742-755 (2017).

3. Petersen GH, Alzghari SK, Chee W, Sankari SS, La-Beck NM. Meta-analysis of clinical and preclinical studies comparing the anticancer efficacy of liposomal versus conventional non-liposomal doxorubicin. J. Control. Rel. 232, 255-264 (2016).

4. Rajan R, Sabnani MK, Mavinkurve V et al. Liposome-induced immunosuppression and tumor growth is mediated by macrophages and mitigated by liposome-encapsulated alendronate. J. Control. Rel. 271, 139-148 (2018).

5. Sabnani MK, Rajan R, Rowland B et al. Liposome promotion of tumor growth is associated with angiogenesis and inhibition of antitumor immune responses. Nanomedicine 11(2), 259-262 (2015). 
-• Shows nanoliposomes may have immunosuppressive and angiogenetic properties, directly counterbalancing their anticancer activity.

6. Moghimi SM. Cancer nanomedicine and the complement system activation paradigm: anaphylaxis and tumour growth. J. Control. Rel. 28(190), 556-562 (2014).

7. Farace C, Sánchez-Moreno P, Orecchioni M et al. Immune cell impact of three differently coated lipid nanocapsules: pluronic, chitosan and polyethylene glycol. Sci. Rep. 6, 18423 (2016).

-• Describes that coated lipid nanocapsules (LNC) impact on the immune cell response is strongly correlated to their coating.

8. Couvreur P, Barratt G, Fattal E, Legrand P, Vauthier C. Nanocapsule technology: a review. Crit. Rev. Ther. Drug Carr. Syst. 19(2), 99-134 (2002).

9. Jäger E, Venturini CG, Poletto FS et al. Sustained release from lipid-core nanocapsules by varying the core viscosity and the particle surface area. J. Biomed. Nanotechnol. 5(1), 130-140 (2009).

10. Calgaroto S, Fauri LE, Frank LA, Paese K, Guterres SS, Pohlmann AR. Chemical stability mass loss and hydrolysis mechanism of sterile and non-sterile lipid-core nanocapsules: the influence of the molar mass of the polymer wall. React. Funct. Polym. 133, 161-172 (2018).

11. Paese K, Ortiz M, Frank LA et al. Production of isotonic, sterile, and kinetically stable lipid-core nanocapsules for injectable administration. AAPS PharmSciTech. 18(1), 212-223 (2017).

12. Pereira NRC, Loiola RA, Rodrigues SF et al. Mechanisms of the effectiveness of poly( $\varepsilon$-caprolactone) lipid-core nanocapsules loaded with methotrexate on glioblastoma multiforme treatment. Int. J. Nanomedicine 13, 4563-4573 (2018).

13. Antonow MB, Franco C, Prado W et al. Arginylglycylaspartic acid-surface-functionalized doxorubicin-loaded lipid-core nanocapsules as a strategy to target alpha(V) beta(3) integrin expressed on tumor cells. Nanomaterials 8(1), pii:E2 (2017).

14. Schultze E, Buss J, Coradini K et al. Tretinoin-loaded lipid-core nanocapsules overcome the triple-negative breast cancer cell resistance to tretinoin and show synergistic effect on cytotoxicity induced by doxorubicin and 5-fluororacil. Biomed. Pharmacother. 96, 404-409 (2017).

15. Drewes CC, Fiel LA, Bexiga CG et al. Novel therapeutic mechanisms determine the effectiveness of lipid-core nanocapsules on melanoma models. Int. J. Nanomedicine. 11, 1261-1279 (2016).

-. Point out the relevance of the LNCs supramolecular structure to toxicity and therapeutic efficacy on melanoma in vivo and in vitro model.

16. Frank LA, Chaves PS, D'Amore CM et al. The use of chitosan as cationic coating or gel vehicle for polymeric nanocapsules: increasing penetration and adhesion of imiquimod in vaginal tissue. Eur. J. Pharm. Biopharm. 114, 202-212 (2017).

17. Friedrich RB, Coradini K, Fonseca FN, Guterres SS, Beck RC, Pohlmann AR. Lipid-core nanocapsules improved antiedematogenic activity of tacrolimus in adjuvant-induced arthritis model. J. Nanosci. Nanotechnol. 16(2), 1265-1274 (2016).

18. Boechat AL, de Oliveira CP, Tarragô AM et al. Methotrexate-loaded lipid-core nanocapsules are highly effective in the control of inflammation in synovial cells and a chronic arthritis model. Int. J. Nanomedicine 10, 6603-6614 (2015).

19. Coradini K, Friedrich RB, Fonseca FN et al. A novel approach to arthritis treatment based on resveratrol and curcumin co-encapsulated in lipid-core nanocapsules: in vivo studies. Eur. J. Pharm. Sci. 78, 163-170 (2015).

20. Bernardi A, Frozza RL, Meneghetti A et al. Indomethacin-loaded lipid-core nanocapsules reduce the damage triggered by A $\beta 1-42$ in Alzheimer's disease models. Int. J. Nanomedicine 7, 4927-4942 (2012).

21. Drewes CC, Alves ACS, Hebeda CB et al. Role of poly( $\varepsilon$-caprolactone) lipid-core nanocapsules on melanoma-neutrophil crosstalk. Int. J. Nanomedicine 12, 7153-7163 (2017).

-• Shows LNCs affects intracellular mechanisms of cells leading to more susceptibility to death and also switches the neutrophil to antitumoral activity.

22. Calgaroto S, Fauri LE, Frank LA, Paese K, Guterres SS, Pohlmann AR. Data of characterization and related assays of lipid-core nanocapsule formulations and their hydrolysis mechanism. Data Br. 21, 918-933 (2018).

23. Boyum A. Separation of lymphocytes, lymphocyte subgroups and monocytes: a review. Lymphology 10(2), 71-76 (1977).

24. Oh H, Siano B, Diamond S. Neutrophil isolation protocol. J. Vis. Exp. 17, 745 (2008).

25. Last'ovicka J, Budinský V, Spísek R, Bartůnková J. Assessment of lymphocyte proliferation: CFSE kills dividing cells and modulates expression of activation markers. Cell. Immunol. 256(1-2), 79-85 (2009).

26. de Lima CB, Tamura EK, Montero-Melendez T et al. Actions of translocator protein ligands on neutrophil adhesion and motility induced by G-protein coupled receptor signaling. Biochem. Biophys. Res. Commun. 417(2), 918-923 (2012).

27. Bayat B, Werth S, Sachs UJ, Newman DK, Newman PJ, Santoso S. Neutrophil transmigration mediated by the neutrophil-specific antigen CD177 is influenced by the endothelial S536N dimorphism of platelet endothelial cell adhesion molecule-1.J. Immunol. 184(7), 3889-3896 (2010).

28. Palacios R. Concanavalin A triggers T lymphocytes by directly interacting with their receptors for activation. J. Immunol. 128(1), 337-342 (1982). 
29. Lacy P, Stow JL. Cytokine release from innate immune cells: association with diverse membrane trafficking pathways. Blood 118(1), 9-18 (2011).

30. Park BS, Lee JO. Recognition of lipopolysaccharide pattern by TLR4 complexes. Exp. Mol. Med. 45, e66 (2013).

31. Chan EC, Ren C, Xie Z et al. Regulator of G protein signaling 5 restricts neutrophil chemotaxis and trafficking. J. Biol. Chem. 293(33), 12690-12702 (2018).

32. Muller WA. Leukocyte-endothelial-cell interactions in leukocyte transmigration and the inflammatory response. Trends Immunol. 24(6), 327-334 (2003).

33. Dong C, Davis RJ, Flavell RA. MAP kinases in the immune response. Annu. Rev. Immunol. 20, 55-72 (2002).

34. Heit B, Liu L, Colarusso P, Puri KD, Kubes P. PI3K accelerates but is not required for, neutrophil chemotaxis to fMLP. J. Cell Sci. 121(Pt2), 205-214. (2008).

35. Anchordoquy TJ, Barenholz Y, Boraschi D et al. Mechanisms and barriers in cancer nanomedicine: addressing challenges, looking for solutions. ACS Nano 11(1), 12-18 (2017).

36. La-Beck NM, Gabizon AA. Nanoparticle interactions with the immune system: clinical implications for liposome-based cancer chemotherapy. Front. Immunol. 8, 416 (2017).

37. Frank LA, Contri RV, Beck RC, Pohlmann AR, Guterres SS. Improving drug biological effects by encapsulation into polymeric nanocapsules. Wiley Interdiscip. Rev. Nanomed. Nanobiotechnol. 7(5), 623-639 (2015).

-• The review provides an updated overview related to the drug delivery advantages of polymeric nanocapsules, including lipid-core nanocapsules.

38. Rodrigues SF, Fiel LA, Shimada AL et al. Lipid-core nanocapsules act as a drug shuttle through the blood brain barrier and reduce glioblastoma after intravenous or oral administration. J. Biomed. Nanotechnol. 12(5), 986-1000 (2016).

39. Weiss A, Shields R, Newton M, Manger B, Imboden J. Ligand-receptor interactions required for commitment to the activation of the interleukin 2 gene. J. Immunol. 138(7), 2169-2176 (1987).

40. Ando Y, Yasuoka C, Mishima T et al. Concanavalin A-mediated $\mathrm{T}$ cell proliferation is regulated by herpes virus entry mediator costimulatory molecule. Vitr. Cell. Dev. Biol. Anim. 50(4), 313-320 (2014).

41. Courtney AH, Lo WL, Weiss A. TCR signaling: mechanisms of initiation and propagation. Trends Biochem. Sci. 43(2), 108-123 (2018).

42. Medzhitov R. Recognition of microorganisms and activation of the immune response. Nature 449(7164), 819-826 (2007).

43. De Oliveira S, Rosowski EE, Huttenlocher A. Neutrophil migration in infection and wound repair: going forward in reverse. Nat. Rev. Immunol. 16(6), 378-391 (2016).

44. Lu YC, Yeh WC, Ohashi PS. LPS/TLR4 signal transduction pathway. Cytokine 42(2), 145-151 (2008).

45. Kolaczkowska E, Kubes P. Neutrophil recruitment and function in health and inflammation. Nat. Rev. Immunol. 13(3), 159-175 (2013).

46. Mocellin S, Marincola FM, Young HA. Interleukin-10 and the immune response against cancer: a counterpoint. J. Leukoc. Biol. 78(5), 1043-1051 (2005).

47. Scali E, Mignogna C, Di Vito A et al. Inflammation and macrophage polarization in cutaneous melanoma: histopathological and immunohistochemical study. Int. J. Immunopathol. Pharmacol. 29(4), 715-719 (2016).

48. Passarelli A, Mannavola F, Stucci LS, Tucci M, Silvestris F. Immune system and melanoma biology: a balance between immunosurveillance and immune escape. Oncotarget 8(62), 106132-106142 (2017).

49. Kawasaki T, Kawai T. Toll-like receptor signaling pathways. Front. Immunol. 5, 461 (2014).

50. Cotton M, Claing A. G protein-coupled receptors stimulation and the control of cell migration. Cell Signal. 21(7), 1045-1053 (2009).

51. New DC, Wong YH. Molecular mechanisms mediating the G protein-coupled receptor regulation of cell cycle progression. J. Mol. Signal. 2, 2 (2007).

52. Choy E. Understanding the dynamics: pathways involved in the pathogenesis of rheumatoid arthritis. Rheumatology (Oxford) 51(Suppl. 5), v3-v11 (2012).

53. Jenkins RW, Barbie DA, Flaherty KT. Mechanisms of resistance to immune checkpoint inhibitors. Br. J. Cancer 118, 9-16 (2018). 